\title{
Some Vector FK Sequence Spaces Generated by Modulus Function
}

\section{E. Herawati ${ }^{*}$, N. Irsyad ${ }^{2}$ and E. Rosmaini ${ }^{1}$}

${ }^{1}$ Department of Mathematics, Universitas Sumatera Utara, Medan, 20155, Indonesia

${ }^{2}$ School of Mathematical Sciences, Universiti Sains Malaysia, Penang, 11800, Malaysia

\begin{abstract}
In this paper, some vector valued sequence spaces $\Gamma_{f}(X)$ and $\Lambda_{f}(X)$ using modulus function are presented. Furthermore, we examined some topological properties of these sequence spaces equipped with a paranorm.
\end{abstract}

Keywords: Modulus function, Paranorm, Vector valued sequence space.

Abstrak. Pada paper ini, diperkenalkan beberapa ruang barisan bernilai vektor $\Gamma_{f}(X)$ dan $\Lambda_{f}(X)$ menggunakan fungsi modulus. Lebih lanjut, dipelajari beberapa sifat-sifat topologi dari ruang-ruang barisan ini dikenakan suatu paranorma tertentu.

Kata Kunci: Fungsi modulus, Paranorma, Ruang barisan bernilai vektor.

Received 06 August 2020 | Revised 01 September 2020 | Accepted 30 September 2020

\section{Introduction}

Let $X$ be a vector space and $\mathbb{R}$ be the set of real numbers. A function $f: \mathbb{R}^{+} \cup\{0\} \rightarrow \mathbb{R}^{+} \cup\{0\}$ is called modulus function if following condition of $f$ satisfying:

1. $f$ is vanishing at zero

2. $f$ satisfies triangle inequality

3. $f$ is an increasing function i.e. $f(\cdot) \uparrow$

4. $f$ is a continuous function from the right at 0 [1]

The function $f$ must be continuous for every element $x$ in $(0, \infty)$. The space of all real number sequences $\left(x_{n}\right)$ such that the infinite series of absolute modulus function is finite denoted by $\ell(f)$ [2]

$$
\sum_{n=1}^{\infty} f\left(\left|x_{n}\right|\right)<\infty
$$

The space $\ell(f)$ becomes a $F K$-space under the $F$-norm

$$
p(x)=\sum_{n=1}^{\infty} f\left(\left|x_{n}\right|\right)<\infty .
$$

*Corresponding author at: Department of Mathematics, Universitas Sumatera Utara, Medan, 20155, Indonesia

E-mail address: elvina@usu.ac.id 
Adnan [3] examined the $F K$-space properties of an analytic and entire real sequence space using modulus function. He showed the characterization to matrix transformation of Ruckle's space $\ell(f)$ into analytic $F K$-space. For the theory of $F K$-space we refer to Banas and Mursaleen [4].

Through the article $\Omega(X), \Gamma_{f}(X), \Lambda_{f}(X)$ denoted by the space of vector value sequences, entire vector value sequence space and analytic vector value sequence space. The vector value sequence space studied by some authors $[5,6,7,8,9,10,11,12,13]$. Further, the concept of sequence space using modulus function was investigated by $[14,15,16,17,18]$.

Recently, Herawati [5] studied the geometric of the vector value sequence spaces defined by order$\varphi$ function under Lattice norm. Further, Gultom [6] studied some topologies properties of a finite arithmatic mean vector value sequence space denoted by $W_{f}(X)$ for $X$ is a linear space and $f$ is a $\varphi$-function.

A functional is called paranormed if satisfies the properties $p: X \rightarrow \mathbb{R}$ that satisfies the properties $p(\theta)=0$, with $\theta$ is the zero vector in $X$, non-negative, $p$ satisfies triangle inequalities, even and every real sequence $\left(\lambda_{n}\right)$ with $\left|\lambda_{n}-\lambda\right| \rightarrow 0$. The space $X$ with paranorm $p$ is called paranormed space, written as $X=(X, p)[1,19]$.

In this work, we define the space of vector value sequences $\Gamma_{f}(X)$ and $\Lambda_{f}(X)$ called entire and analytic vector valued sequence spaces generated by modulus function and study the topological properties of the sets equipped with paranorm.

\section{Main Results}

In this main result section, firstly, we introduce paranorm on this space and examine some topological properties such as complete properties. Let $X$ be a Banach space and $f$ be a modulus function. Let $y(n)=f\left(\|x(n)\|_{X}\right) \in \mathbb{R}$ for all natural numbers $n$, then we get a sequence $y=(y(n))$. We define the sets

$$
\begin{aligned}
& \Gamma_{f}(X)=\left\{x=(x(n))_{n \in \mathbb{N}}: x(n) \in X \text { and }(y(n))^{\frac{1}{n}} \rightarrow 0, n \rightarrow \infty\right\} \\
& \Lambda_{f}(X)=\left\{x=(x(n)) n \in \mathbb{N}: x(n) \in X \text { and } \sup _{n \in \mathbb{N}}\left\{(y(n))^{\frac{1}{n}}\right\}<\infty\right\}
\end{aligned}
$$

\section{Theorem 1.}

The sets $\Gamma_{f}(X)$ and $\Lambda_{f}(X)$ are vector spaces.

\section{Proof.}

Let $x, z$ be any elements in $\Gamma_{f}(X)$, then

$$
\lim _{n \rightarrow \infty}(y(n))^{\frac{1}{n}}=0 \text { and } \lim _{n \rightarrow \infty}(w(n))^{\frac{1}{n}}=0
$$

for $n \rightarrow \infty$, with $y(n)=f(x(n)$ and $w(n)=f(z(n))$ for each natural number $n$. We will apply the following inequality : if $a_{n}, b_{n} \in \mathbb{R}$ and $0 \leq q_{n} \leq \sup q_{n}=H$ for each natural number $n$, then

$$
\left|a_{n}+b_{n}\right|^{q_{n}} \leq M\left(\left|a_{n}\right|^{q_{n}}\right)+\left|b_{n}\right|^{q_{n}}
$$


where $M=\max \left\{1,2^{H-1}\right\}$. Therefore,

$$
(y(n)+w(n))^{\frac{1}{n}} \leq(y(n))^{\frac{1}{n}}+(w(n))^{\frac{1}{n}}
$$

Since $\left(q_{n}\right)=\left(\frac{1}{n}\right)$, then $H=\sup \frac{1}{n}=1$. Thus

$$
(y(n)+w(n))^{\frac{1}{n}} \leq(y(n))^{\frac{1}{n}}+(w(n))^{\frac{1}{n}}
$$

Since $(y(n))^{\frac{1}{n}} \rightarrow 0$ and $(w(n))^{\frac{1}{n}}$ for $n \rightarrow \infty$, then $(y(n)+w(n))^{\frac{1}{n}} \rightarrow 0$ for $n \rightarrow \infty$. Therefore, we obtain $x+y \in \Gamma_{f}(X)$. Further, for element $x \in \Gamma_{f}(X)$ and $\alpha \in \mathbb{R}$, then

$$
(y(n))^{\frac{1}{n}} \rightarrow 0, n \rightarrow \infty
$$

Because of an increasing function $f$ and the positivity of $|\alpha|$, then from the Archimedean properties, there exists natural number $n_{0}$ with

$$
f(|\alpha|\|x(n)\|) \leq f\left(2^{n_{0}}\|x(n)\|\right)
$$

Since $f$ satisfies $\triangle_{2}$-condition, we get

$$
\left(f\left(2^{n_{0}} \| x(n)\right)\right)^{\frac{1}{n}}=K^{\frac{n_{0}}{n}}(f(\|x(n)\|))^{\frac{1}{n}} \rightarrow 0
$$

for each natural number $n$. It shows that $\alpha x \in \Gamma_{f}(X)$. Because $x+z \in \Gamma_{f}(X)$ and $\alpha x \in \Gamma_{f}(X)$ for each $x, y \in \Gamma_{f}(X)$ and each $\alpha \in \mathbb{R}$, we get $\Gamma_{f}(X)$ is a vector or linear space and the proof of the theorem is finished. In the same way, it can be shown that $\Lambda_{f}(X)$ is a vector space.

\section{Theorem 2.}

A functional $p: \Gamma_{f}(X) \rightarrow \mathbb{R}$ defined by

$$
p(x)=\sup _{n \geq 1}\left\{(y(n))^{\frac{1}{n}}\right\}
$$

is a paranorm.

\section{Proof.}

Let $x$ be an element in $\Gamma_{f}(X)$. It is clear that the functional $p$ is non-negative, $p(\theta)=0$, with $\theta$ is the zero vector in $X$ and even, for each $x \in \Gamma_{f}(X)$. Now, we will show that $p$ satisfies the triangle inequality. To do that, take any $x, z \in \Gamma_{f}(X)$, then

$$
\lim _{n \rightarrow \infty}(y(n))^{\frac{1}{n}}=0 \text { and } \lim _{n \rightarrow \infty}(w(n))^{\frac{1}{n}}=0
$$

for $n \rightarrow \infty$, with $y(n)=f(x(n))$ and $w(n)=f(z(n))$ for each $n \in \mathbb{N}$. we obtain

$$
\sup \left\{(y(n)+w(n))^{\frac{1}{n}}\right\} \leq \sup \left\{(y(n))^{\frac{1}{n}}+(w(n))^{\frac{1}{n}}\right\}
$$

Therefore, there's vector sequences of $x, y \in \Gamma_{f}(X)$, we get $p$ satisfies the triangle inequality. Next, we will show that $p$ satisfies the continuity of scalar multiplication. To do that, take any real 
sequence $\left(\lambda_{n}\right)$ and $(x(n)) \in \Gamma_{f}(X)$ with $\left|\lambda_{n}-\lambda\right| \rightarrow 0$ for $n \in \infty$. We have

$$
\begin{aligned}
\left.\left(f(\| x(n)) \|_{X}\right)\right)^{\frac{1}{n}} & =\left(f\left(\left\|\lambda_{k} x(n)-\lambda x(n)\right\|\right)\right)^{\frac{1}{n}} \\
& \left.=\left(f\left(\left\|\left(\lambda_{n}-\lambda\right) x(n)\right\|\right)+\|\lambda(x(n)-x)\|\right)\right)^{\frac{1}{n}} \\
& \leq\left(\left(f\left|\lambda_{n}-\lambda\right|\|x(n)\|+|\lambda|\|(x(n)-x)\|\right)^{\frac{1}{n}}\right.
\end{aligned}
$$

and

$$
\begin{aligned}
p\left(\lambda_{n} x(n)-\lambda x(n)\right) & =\sup \left\{\left(f\left(\left\|\lambda_{n} x(n)-\lambda x(n)\right\|\right)\right)^{\frac{1}{n}}\right\} \\
& \leq\left|\lambda_{n}-\lambda\right| p(x(n)+|\lambda| p(x(n)-x) \rightarrow 0
\end{aligned}
$$

Hence, $p\left(\lambda_{n} x(n)-\lambda x(n)\right) \rightarrow 0$. The proof of the theorem is finished.

\section{Theorem 3.}

The vector spaces of $\Gamma_{f}(X)$ and $\Lambda_{f}(X)$ are complete paranormed sequence space under the paranorm defined in Theorem 2.

\section{Proof.}

Take any Cauchy sequence $\left(x^{i}\right)$ in $\Gamma_{f}(X)$ with $x^{i}=\left(x^{i}(n)\right)=\left(x^{i}(1), x^{i}(2), \ldots,\right)$. Therefore, for any positive real number $\varepsilon$, there exists $i_{0} \in \mathbb{N}$, for all $j \geq i \geq i_{0}$, we get

$$
p\left(x^{j}-x^{i}\right)=\sup \left\{\left(f\left(\left\|x^{j}(n)-x^{i}(n)\right\|\right)\right)^{\frac{1}{n}}\right\}<\varepsilon
$$

Since $\left.\sup \left(f\left\|x^{j}(n)-x^{i}(n)\right\|\right)\right)^{\frac{1}{n}}<\varepsilon$, we have $\left(f\left(\left\|x^{j}(n)-x^{i}(n)\right\|\right)\right)^{\frac{1}{n}}<\varepsilon$ for $\varepsilon>0$. Since $f$ is a modulus function, then $\left\|x^{j}(n)-x^{i}(n)\right\|=0$ for each natural number $n$. In other words, $\| x^{j}(n)-$ $x^{i}(n) \|<\varepsilon$. It shows that for each natural number $n$ of the sequence $\left(x^{j}(n)\right)$ is a Cauchy. Since $X$ is a complete normed space, then $\left(x^{j}(n)\right)$ converges to $x(n) \in X$. Hence, $\lim _{j \rightarrow \infty} x^{j}(n)=x(n)$ for all $n$. Therefore, there's sequence $x=(x(n))=(x(1), x(2), \ldots$,$) such that$

$$
\begin{aligned}
\sup \left\{\left(f\left(\left\|x-x^{i}\right\|\right)\right)^{\frac{1}{n}}\right\} & =\sup \left\{\left(f\left(\left\|\lim _{i \rightarrow \infty} x-x^{i}\right\|\right)\right)^{\frac{1}{n}}\right\} \\
& =\sup \left\{\lim _{i \rightarrow \infty}\left(f\left(\left\|x-x^{i}\right\|\right)\right)^{\frac{1}{n}}\right\} \\
& =\lim _{i \rightarrow \infty} \sup \left\{\left(f\left(\left\|x-x^{i}\right\|\right)\right)^{\frac{1}{n}}\right\}
\end{aligned}
$$

for every $i \geq i_{0}$. By using the definition of paranorm, we get

$$
p\left(x-x^{i}\right)=\sup \left\{\left(f\left(\left\|x-x^{i}\right\|\right)\right)^{\frac{1}{n}}\right\}<\varepsilon
$$

It shows that $x^{i} \rightarrow x$ for $i \rightarrow \infty$. Then it will be shown that $x \in \Gamma_{f}(X)$. Using the continuous 
property of $f$, we get

$$
\begin{aligned}
(f(\|x\|))^{\frac{1}{n}} & =\left(f\left(\left\|\lim _{i \rightarrow \infty} x^{i}\right\|\right)\right)^{\frac{1}{n}} \\
& =\lim _{i \rightarrow \infty}\left(f\left(\left\|x^{i}\right\|\right)\right)^{\frac{1}{n}} \rightarrow 0
\end{aligned}
$$

for $i \rightarrow \infty$. Hence, $x \in \Gamma_{f}(X)$. The proof of this theorem is finished.

\section{Conclusions}

According to the main results, it can be concluded $\Gamma_{f}(X)$ and $\Lambda_{f}(X)$ are complete paranormed sequence space under the paranorm.

\section{REFERENCES}

[1] H. Nakano, "Modulared sequence spaces," Proc. Japan Acad., vol. 27, no. 9, pp. 508-512, 1951.

[2] W. H. Ruckle, "Fk spaces in which the sequence of coordinate vectors is bounded," Canadian Journal of Mathematics, vol. 25, no. 5, pp. 973-978, 1973.

[3] A. Alhomaidan, "Some fk spaces defined by a modulus function," International Journal of Pure and Applied Mathematics, vol. 30, no. 1, pp. 43-48, 2006.

[4] J. Banas and M. Mursaleen, Sequence Spaces and Measures of Noncompactness with Applications to Differential and Integral Equations. Springer India, 2014.

[5] E. Herawati, Supama, and M. Mursaleen, "Local structure of riesz valued sequence spaces defined by an order $\phi$-function," Linear and Multilinear Algebra, vol. 65, no. 3, pp. 545-554, 2017.

[6] S. N. R. Gultom, R. Siregar, and E. Herawati, "Köthe-töeplitz duals of vector valued sequence spaces defined by $\phi$-function," Journal of Physics: Conference Series, vol. 1116, no. 2, pp. 1-6, 2018.

[7] E. Kolk, "Topologies in generalized orlicz sequence spaces," Filomat, vol. 25, no. 4, pp. 191-211, 2011.

[8] I. E. Leonard, "Banach sequence spaces," Journal of Mathematical Analysis and Applications, vol. 54, no. 1, pp. 245-265, 1976.

[9] N. R. Das and A. Choudhury, "Matrix transformation of vector valued sequence space," Bulletin of the Calcutta Mathematical Society, vol. 84, no. 1, pp. 47-54, 1992.

[10] M. Et, "Spaces of cesáro difference sequences of order $r$ defined by a modulus function in a locally convex space," Taiwanese Journal of Mathematics, vol. 10, no. 4, pp. 865-879, 2006.

[11] M. Et, A. Gökhan, and H. Altinok, "On statistical convergence of vector-valued sequences associated with multiplier sequences," Ukrainian Mathematical Journal, vol. 58, no. 139, 2006. 
[12] B. C. Tripathy and M. Sen, "Vector valued paranormed bounded and null sequence spaces associated with multiplier sequences," Soochow Journal of Mathematics, vol. 29, no. 3, pp. 313-326, 2003.

[13] B. C. Tripathy and S. Mahanta, "On a class of vector-valued sequences associated with multiplier sequences," Acta Mathematicae Applicatae Sinica, vol. 20, no. 4, pp. 487-494, 2004.

[14] T. Bilgin, "The sequence space 1 (p, f, q, s) on seminormed spaces," Bull. Calcutta Math. Soc, vol. 86, no. 4, pp. 295-304, 1994.

[15] S. Pehlivan and B. Fisher, "On some sequence spaces," Indian Journal of Pure and Applied Mathematics, vol. 25, no. 10, pp. 1067-1071, 1994.

[16] A. Waszak, "On the strong convergence in some sequence spaces," Fasciculi Mathematici, vol. Nr 33, pp. 125-137, 2002.

[17] V. K. Bhardwaj, "A generalization of a sequence space of ruckle," Bull. Calcutta Math. Soc, vol. 95, no. 5, pp. 411-420, 2003.

[18] Y. Altin, "Properties of some sets of sequences defined by a modulus function," Acta Mathematica Scientia Series B English Edition, vol. 29, no. 2, pp. 427-434, 2009.

[19] S. Simons, "The sequence spaces $l\left(p_{v}\right)$ and $m\left(p_{v}\right)$," Proceedings of the London Mathematical Society, vol. s3-15, no. 1, pp. 422-436, 1965. 